\title{
Propuesta para un acercamiento semiótico al mural Misterio y Viaje de los Tres Espíritus Sagrados*
}

*Una primera versión del mismo apareció publicada en

"SEMIÓTICA, memoria del grupo de investigación, 1995":

Universidad Autónoma Metropolitana, Azcapotzalco - México.

El presente artículo es una reformulación de ese ensayo.

Juan Manuel López Rodríguez Universidad Autonoma Metropolitana - Azcapotzalco/México 


\section{Resumen}

El mural que nos ocupa en este artículo, y que describe "misterio y viaje de los tres espíritus sagrados" encierra una narración en imágenes de la cosmogonía huichola. Se trata de una maravillosa obra de arte, compuesta por ochenta cuadros de 90 centímetros cuadrados cada uno, realizados totalmente con chaquira (pequeñísimas esferas de cristal de color), pegadas sobre tabla con cera de Campeche. En este mural podemos ver tanto el aquí y el ahora como el mañana y el ayer huichol, do modo didáctico, en una organización visual que articula la materia visual con el aspecto conceptual para generar el significado tanto de la obra como de la doctrina que rige sus vidas.

\section{Palavras-chave}

semiótica, cultura huichol, mural, indigenismo

\section{Abstract}

The mural that concerns this article, and which describes the "mystery and travel of the three sacred spirits" encloses a tale in images of the huichol cosmogony. It is a wonderful work of art, composed by eighty squares of $90 \mathrm{~cm}$. each, made entirely in chaquira (tiny colored glass beads) glued individually to the board with bee wax from Campeche. In the mural we can simultaneously see the here and now, the yesterday, and the tomorrow of the huichol people, in a visual arrangement that articulates the images with the inherent concepts of their mythology, thus generating a unique meaning for both the work of art, and the mystic principles that rule the wirraritari lives.

\section{Key words}

semiotics, huichol culture, mural, indigenism 
W

irraritari se autonombran los huicholes en su lengua, de la familia yutoazteca. ${ }^{1}$

Sobre su significado no existe consenso, para unos es "adivinos", otros lo traducen como "los que saben", mientras hay quienes afirman que significa "doctores" o "curanderos".

Los wirraritari ocupan una zona geográfica de unos 4,107 kilómetros cuadrados entre la serranía del oeste de Jalisco, el borde suroeste de Zacatecas, el declive oeste de la sierra nayarita y el sur de Durango.

Existen cinco grandes comunidades que funcionan como centros político-religiosos: Santa Catarina Cuexcomatitlán, San Andrés Cohamiata, San Sebastán Teponahuaxtlan, Tuxpan y Guadalupe Ocotlán, En Durango habitan pequeños grupos en San Antonio de Padua, San Lucas de Jalpa y Santa María de Huasamota; también en Tepic, Nayarit, existe un enorme asentamiento huichol urbano. La población wirrarika se estima en un total de 33 mil personas.

Desde hace siglos se distinguen tres clanes nucleares, cada uno de ellos con un territorio, relación y procedencia de una deidad diferente. En Santa Catarina habitan los tuapuritari, "los sagrados"; en San Sebastian los huautuari; en San Andrés los tateiquitari, que son los de "la casa de nuestra madre".

Una de las características que rigen su vida diaria es la mitología, compuesta por elementos de la religión indígena y del catolicismo del siglo XVIII. Esta contiene una explicación acerca del origen de los astros, del mundo, de las plantas, de los animales y las enfermedades. Sus deidades son poderosas pero también peligrosas. Para agradarles y mantener buenas relaciones, elaboran ofrendas y realizan rituales.

1. La realización de este trabajo no hubiera sido posible sin la valiosa colaboración de Adán Xicotencal. 
A las deidades se les designa como "antepasados" y con términos de parentesco: el padre sol, el abuelo fuego, el bisabuelo cola de venado, nuestras madres del agua, nuestra madre tierra.

Los elementos constantes son el maíz, el venado, y el jícuri (peyote). Los dos primeros representan el sustento del hombre huichol, el jícuri es la carne y alimento de los dioses, el intermediario entre el hombre y las deidades.

Según la mitología, el maíz fue primero venado. El venado es el bisabuelo Tatusi Maxacuaxi (el maestro que dirige a todos los antepasados). El venado principal es Tamatsi Kauyumari, que junto con sus hermanos forman una trilogía mística que representa el marakame (chamán) y sus ayudantes.

De los cuernos del venado muerto, víctima de la cacería mágica de los tiempos primordiales, brotaron los jícuris (peyote alucinógeno), los muvieris (plumas sagradas) y demás ofrendas del culto.

Los cantos místicos del marakame (chamán) expresan el origen, función y lugar de las deidades. Pueden durar hasta tres noches y contienen una gran riqueza en los detalles.

En el pensamiento huichol, el apego a las costumbres sagradas es el punto medular para el mantenimiento de todo equilibrio.

Los wirrarika asumen su existencia individual y social como un reflejo pleno del orden cósmico. Cualquier actitud que pueda alterar la normatividad cultural representa la causa de todo acontecimiento no deseado.

Con el propósito de asegurar "el costumbre", la educación se inicia desde la infancia, en el ámbito familiar. También se transmite mediante cantos y rituales, en los que cada individuo participa desde pequeño.

La cosmogonía huichola trasciende las fronteras de su geografía y ubica como sitios sagrados de primer orden los cinco puntos cardinales: oriente, Wirikkuta; poniente, Aramara (la deidad del mar); norte, Huarra-mana-ka; sur, Rapavillame (el espíritu de las aguas del sur); y en el centro, Teakata (donde vive el abuelo fuego).

Otros sitios sagrados están en la ruta de la peregrinación a Wirikuta, en donde existen dos polos: el manantial sagrado de Tatei Matinieri (nuestra madre lluvia), inicio del viaje a pie, y Lo' unar (Cerro Quemado), donde nació el sol y está el fin de la ruta sagrada. 
Las comunidades huicholas tienen gran cantidad de centros ceremoniales donde se encuentran los Kalihuey (lugares donde se realizan las diferentes ceremonias).

Para los wirraritari, los sitios sagrados fueron construidos por los "antepasados".

En ellos, además de reconocer su orígenes más remotos y los de sus propios creadores, reproducen los valores y deberes heredados. Los frecuentan para rendir tributo, dar cuenta de los actos realizados y para enmendar sus faltas.

El apego a las costumbres es un deber con el que cada huichol debe cumplir a lo largo de su vida,en caso de no hacerlo pueden contraer enfermedades, "falta de costumbre", le llaman. Estas sólo se curan acudiendo a los sitios sagrados, aunque estos se encuentren en los puntos mas lejanos e inaccesibles. Siempre llevan ofrendas como jícaras votivas, flechas, velas y nierikas (representaciones).

\section{Un mural huichol}

En todas las obras producidas a los largo de la historia de la humanidad dentro de lo que pudiéramos llamar Artes Visuales que conllevan alguna intencionalidad didáctica, encontramos una información estructural similar, conocida como nivel sintáctico, que facilita la información conceptual, conocida como nivel semántico y que coincide con ella.

Se trata de una forma de expresión en la cual el receptor se ve obligado a intervenir participativamente en el, proceso reconstructivo del mensaje, al encontrarse ante una evidente ruptura del espacio-tiempo que reproduce una estructura (una sintaxis) de relaciones constantes, que sirven como anclaje para la comprensión y la integración del conocimiento transmitido.

Estamos frente a un discurso visual total, en el que lo mismo vemos el dominio de los dioses o los astros sobre la naturaleza humana, que el dominio de la naturaleza sobre el hombre, o el dominio de éste sobre la naturaleza. Vemos el aquí y el ahora simultáneamente al ayer y al mañana, todo en un solo espacio narrativo en el que se interconectan en estructuras similares una serie de paradigmas y de ubicaciones diferentes. 


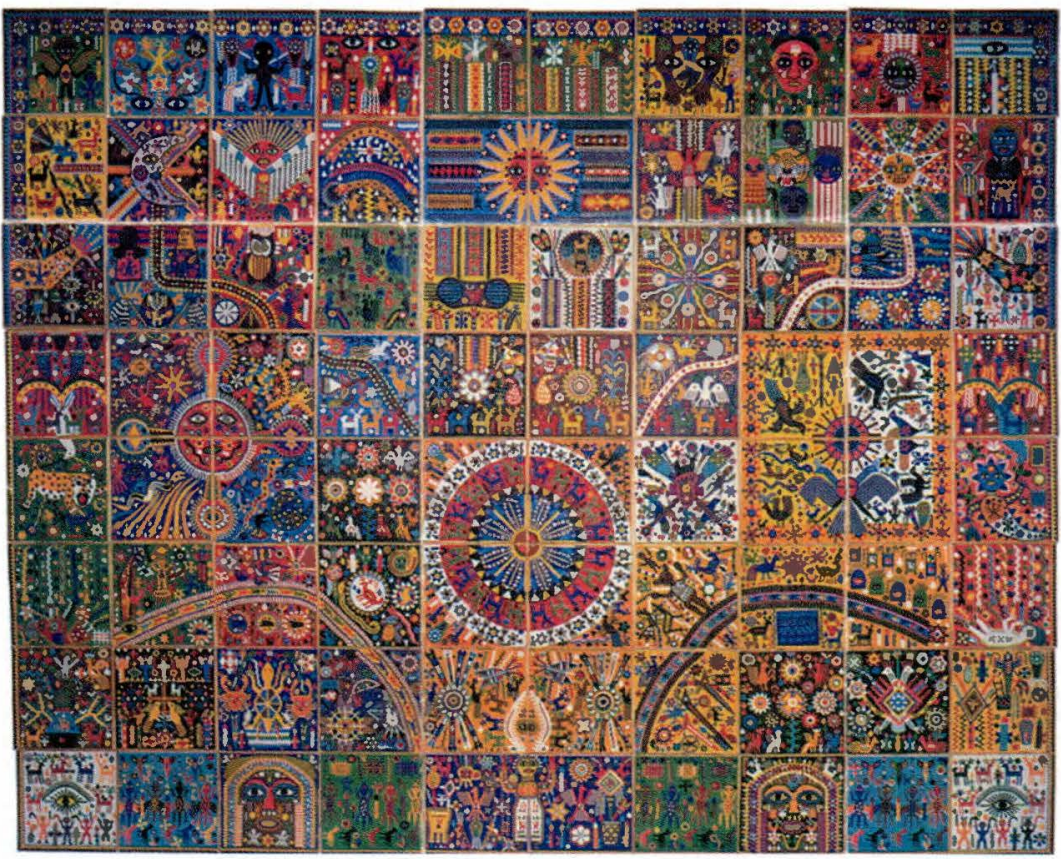

Es interesante encontrar como las formas visuales didácticas, que establecen una relación entre la naturaleza y la cultura, aparecen por igual en nuestras culturas indígenas, tanto en las precortesianas como en las que se mantienen vivas en la actualidad.

Para sustentar esta hipótesis, hemos escogido un mural representativo del arte contemporáneo huichol, realizado por Santos de la Torre Santiago, natural de San Andrés Cohamiata, que expresa el corazón y el pensamiento de su cultura en el grado más alto de las manifestaciones artísticas de los wirraritari, o sea, desde el iyari, arte que va mucho más allá de lo puramente decorativo.

Nuestro trabajo propone un primer intento de acercamiento metodológico, que no pretende, ni mucho menos, llegar al significado profundo de la obra.

El mural está construido sobre ochenta cuadros de noventa centímetros cuadrados cada uno, en los que diseño se ha conforma- 
do en su totalidad con chaquira (pequeñísimas esferas de cristal de color).

Como en todo trabajo artístico visual y de índole explícitamente didáctica, la forma no se opone al contenido. Por el contrario, se trata de una organización visual que articula lo realizado por el artista, aquello que percibimos con la vista -materia visual- con aquello que corresponde a la materia conceptual, generando así la significación.

Hablemos, entonces, de las formas de la expresión y de las formas del contenido. En estas formas es donde encontraremos las diferencias que nos llevarán al significado, al articular la materia sensible con la conceptual, pues el sistema de significación es, como se sabe, generado por la semiosis entre la forma y la sustancia de expresión y la forma y la sustancia de contenido.

En las prácticas significantes impregnadas de connotaciones, el sentido se expande a través de la relación entre la forma del plano de la expresión y el plano de contenido, y no de su sustancia.

En nuestro intento analítico, por lo tanto, el plano de la expresión será determinante para llegar al plano del contenido. Nos acercaremos a él tomando en cuenta algunos aspectos de la semiótica planária. Mas el plano del contenido, difícil de abarcar en su totalidad en este breve acercamiento, podrá ser considerado también a partir de premissas de la llamada semiótica antropológica.

Por lo anterior, nos vemos en la necesidad de segmentar el discurso visual del mural huichol, a efecto de localizar las figuras y las categorías plásticas contenidas en el mismo. A esta fase de localización la denominaremos como la búsqueda y el encuentro de categorías topológicas, que consistirán en el arriba y abajo, derecha-izquierda, centro-periferia, etc. que junto con las categorías visuales, constituyen el nivel más profundo dentro del plano de la expresión.

Es obvio que frente al mural huichol "Misterio y Viaje de los Tres Espíritus Sagrados" nos encontramos sujetos a una lectura topológica. Del centro a la periferia, de izquierda a derecha, de arriba hacia abajo. Estamos ante un mundo riquísimo que plantea una cantidad infinita de posibilidades de exploración, pero que también 
plantea una determinada direccionalidad de lectura con base en la jerarquización de las figuras que contiene, de cuatro líneas y de otros elementos que conducen nuestra vista de manera casi obligada. A través de un recorrido más atento, nos damos cuenta que ciertas figuras tienen mayor importancia que otras tanto por su colocación como por la superficie que ocupan.

Hay dos figuras sobre el eje vertical central, una colocada al centro del mural (Tapari Tatewari), y otra en la parte inferior (Tatewari, entidad máxima), de las que irradian en una diagonal curva hacia arriba y hacia ambos lados, cuatro líneas. Esta composición centro-periferia simultánea a la de arriba-abajo parece marcar ciertos espacios de predominio en el mural.
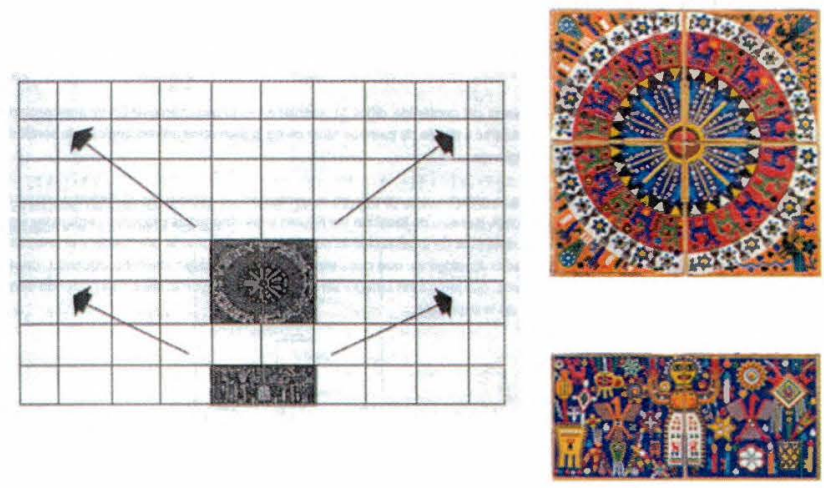

Todo lo anterior se confirma en la concentración eidéticotopológica que concurre a dar relevancia a ciertas figuras, que van a orientar la lectura en una dirección que determina una especie de secuencia narrativa, a la que podemos considerar el elemento constitutivo primario del discurso. Nos lo están diciendo las presencias de ciertos símbolos unidos a los índices de direccionalidad marcados en el mural. Intentaremos señalar los espacios secuenciales primarios, además de los ya mencionados:

En la parte inferior se encuentran los tres espíritus sagrados: 
Tatutsi Maxacuasi, el Abuelo Cola de Venado, Peyote, Jícuri, Memoria Histórica, a la izquierda de Tatewari, deidad máxima, Abuelo Fuego. A la derecha Tacutsi Nacawé, la Abuela Crecimiento, creación de la vida.
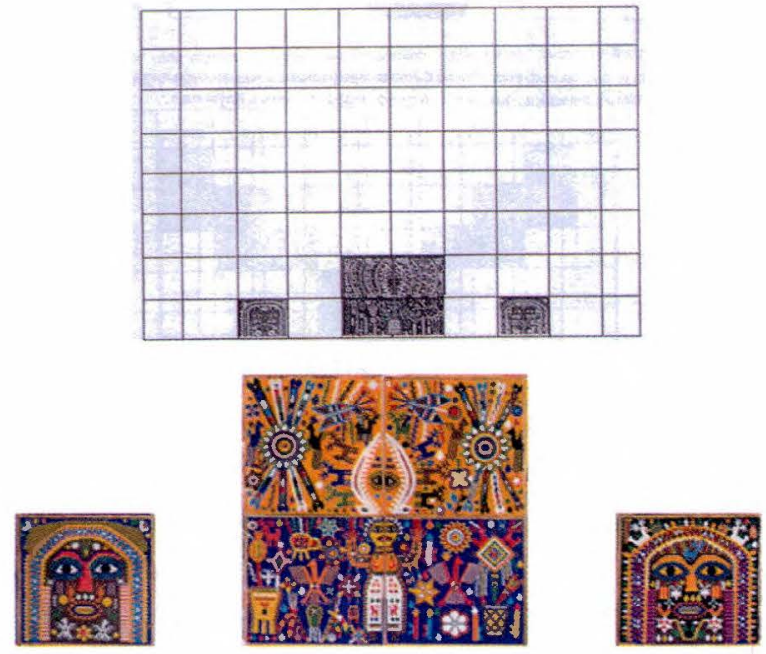

De la morada de Tatewari parte un camino de alacranes hacia la izquierda (caminan sobre la tierra), hacia un personaje oscuro y femenino que viste falda: Tamatsi Kayaumari.
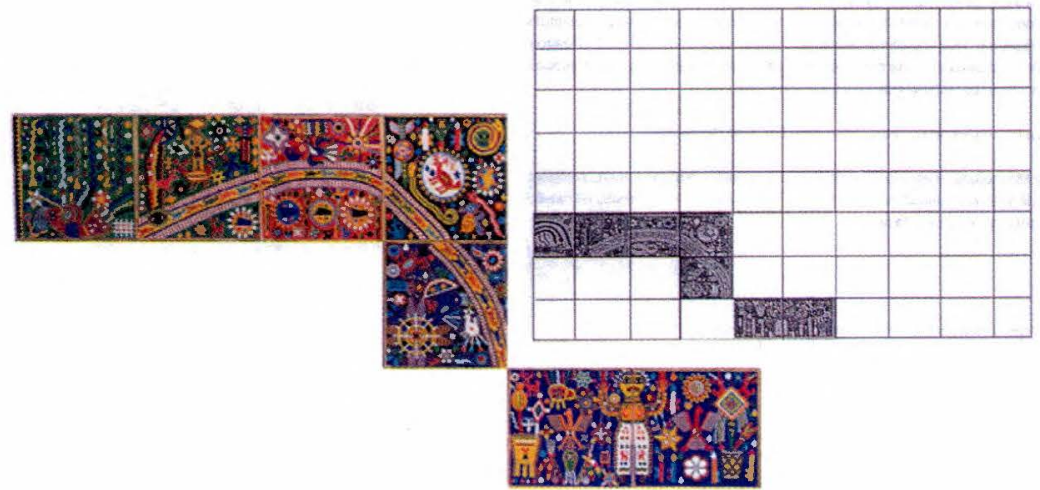
Hacia el lado opuesto, el camino es de mariposas (vuelan), y nos conduce hacia un personaje claro y masculino, que es la otra personalidad de Tamatsi Kayaumari.
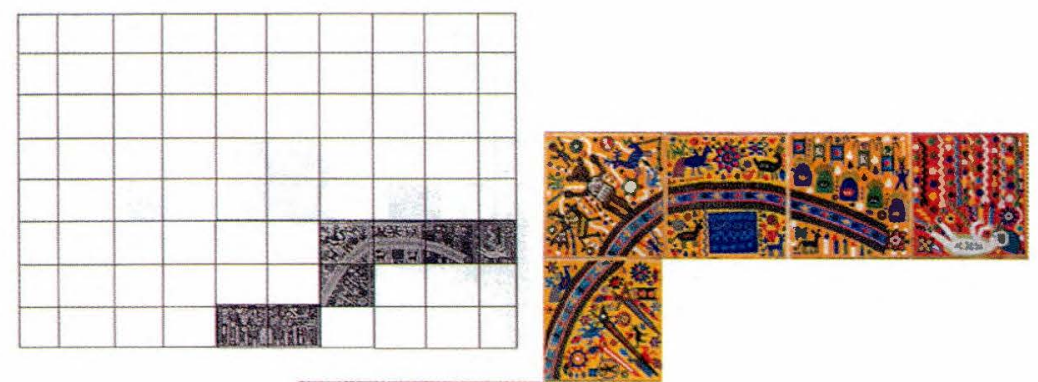

Al centro está Tapari Tatewari, depende directamente del Gran Abuelo Fuego, y representa la alternancia de los cuatro elementos: aire, fuego, agua y tierra.
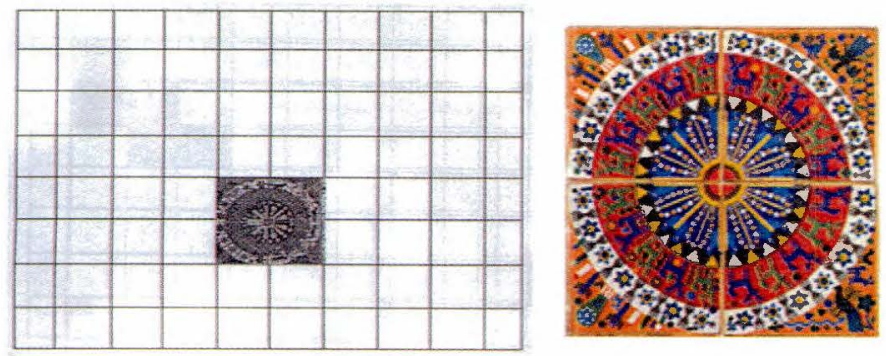

De este elemento central sale un camino hacia la luna, Jarianaca Metzeri, lo femenino, y sale otro camino hacia el ojo del sol: Xurawe Temai. 


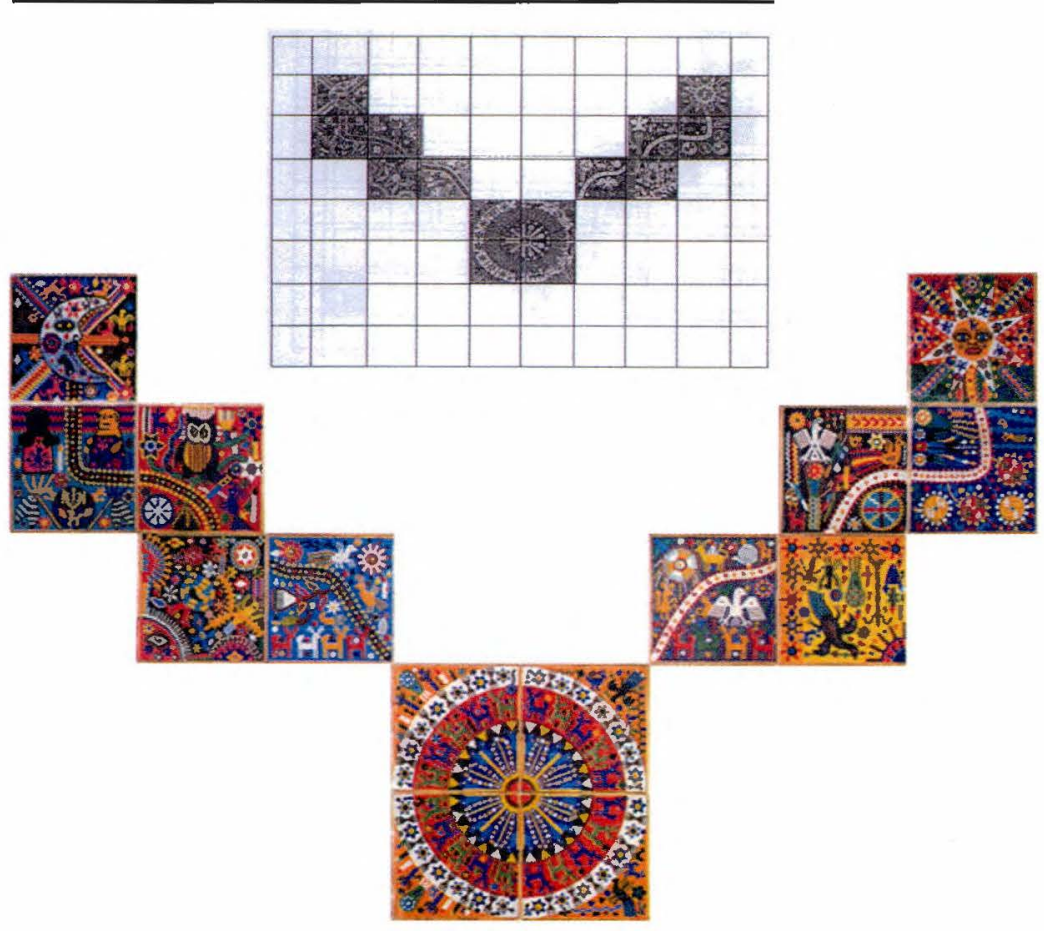

Los caminos inferiores que nacen de Tatewari, el Gran Abuelo Fuego, nos conducen, a la izquierda, a un equipal (trono) oscuro, que mira hacia la noche;
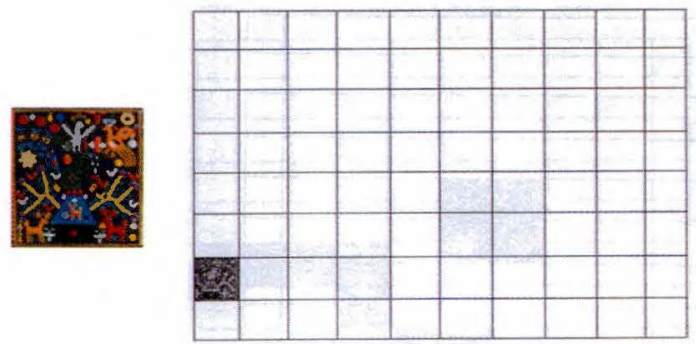
Y hacia la derecha, a otro equipal (trono) luminoso, lleno de energía, que mira hacia la salida del sol.
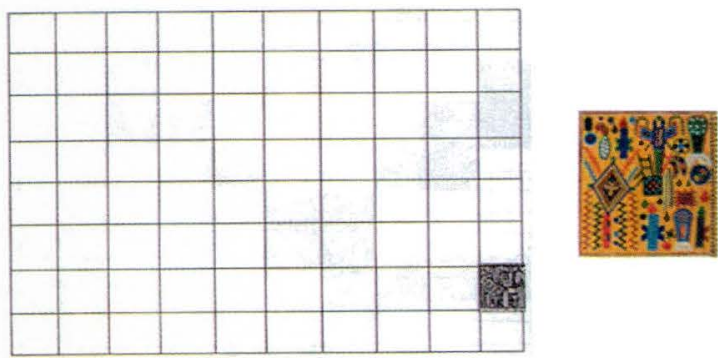

El camino superior de la izquierda, para llegar a la luna, pasa por los campos de la maldad y el castigo, el tecolote (búho) y los destructores de la cosecha.
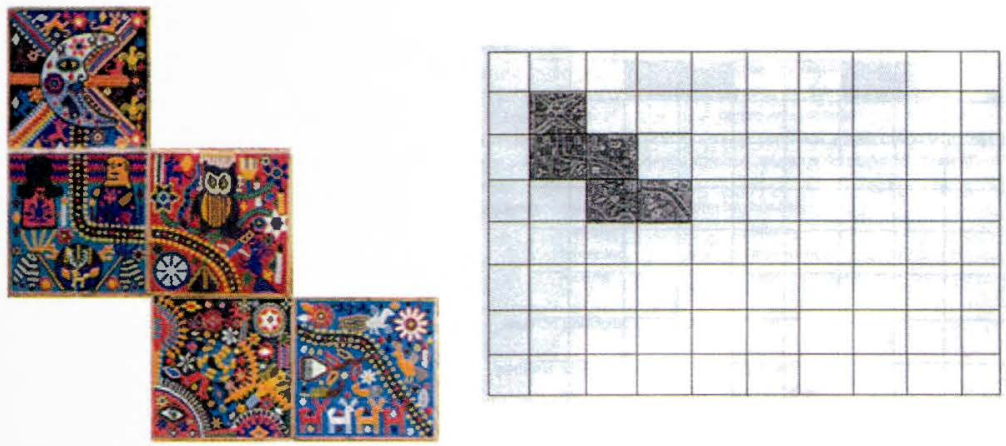

El camino de la derecha, cruza los elementos de la resurrección de Tatewari, que representan una leyenda idéntica a la del Quinto Sol de los aztecas. 

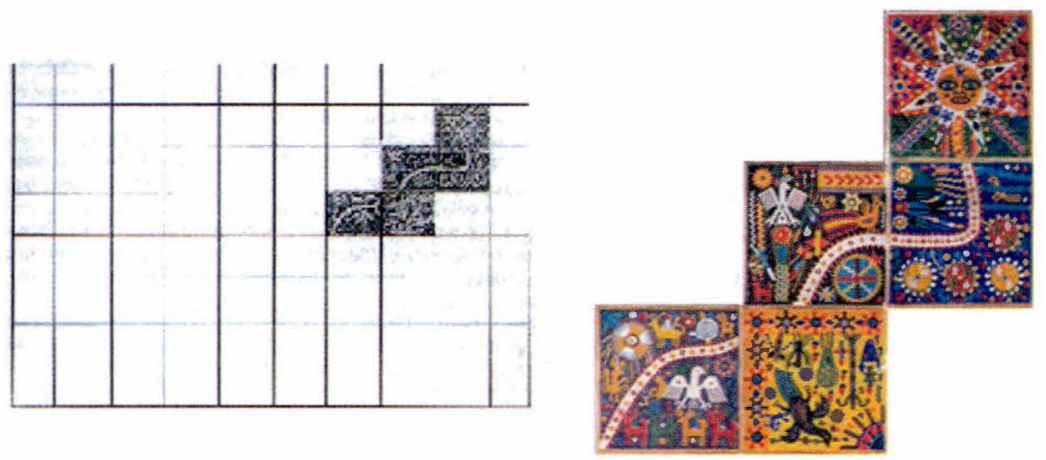

En la parte superior del mural está la representación de Wiricuta, destino fínal del viaje, lugar del Jícuri, del Peyote, (cactus alucinógeno).
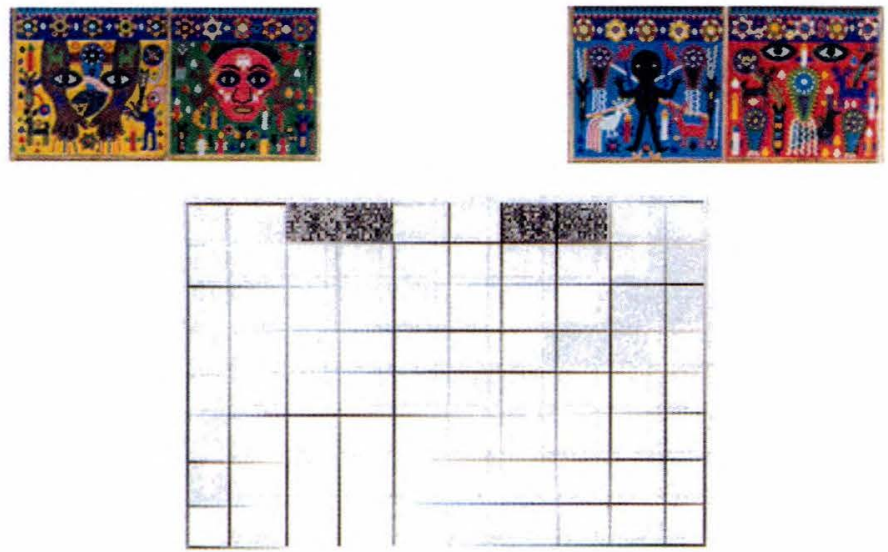

Sería imposible en un espacio tan corto como éste plantear en el nivel profundo del plano de la expresión todos los espacios secuenciales contenidos en el mural. 
Consideremos únicamente los que hemos visto hasta aquí:

1. Tatewari: Abuelo Fuego.

2. Tatutsi: Abuelo Peyote: Memoria.

3. Tacutsi: Abuela Creación de la Vida.

4. Tacutsi Nacawé: Femenino.

5. Tacutsi Kayaumari: Masculino.

6. Tapari Tatewari: los Cuatro Elementos: el Equilibrio.

7. Jarianaca Metzeri: la Luna, lo Femenino.

8. Xarawe Temai: el Ojo del Sol, lo Masculino.

9. El Tecolote (búho).

10. Los Destructores de la Milpa (de la cosecha).

11. La Energía, la Reencarnación de Tatewari.

12. La Leyenda del Quinto Sol.

13. Equipal (trono) volteado hacia la Oscuridad.

14. Equipal (trono) volteado hacia el Amanecer.

15. La posibilidad de ver, el final del viaje, visión completa de la gesta emprendida por los antepasados (los Espíritus Sagrados, los Dioses).

A partir del somero análisis que hemos hecho del Plano de la Expresión, desde sus Categorías Topológicas, podemos considerar, para efecto de nuestro análisis los siguientes elementos:

Derecha vs. Izquierda.

Superior vs. Inferior.

Centro vs. Periferia.

De ello podemos derivar, de acuerdo con la semiótica visual, que a dos figuras de la expresión pueden ser homologados términos opuestos del plano del contenido. Entonces tendremos que:

Izquierda: Maldad

Pasado

Femenino

Muerte

Inferior: Principio

Periferia: Viaje azaroso

Inseguridad
Derecha: Bondad Futuro

Masculino

Vida

Superior: Final

Centro: Equilibrio Estabilidad 
Empezamos a darnos cuenta que todo gira alrededor de un elemento central: Tapari Tatewari, el Equilibrio de los Elementos de la Naturaleza, el Equilibrio del Mundo. Su naturaleza plástica y su colocación central dentro del mural nos habla de la relación entre el mundo cotidiano huichol y la presencia constante de un contacto con la naturaleza en la que ésta es parte integral del ser humano tanto física como ideológicamente.

A la izquierda tenemos a la luna, el toloache, la datura, la maldad, dueña de los ciclos menstruales, en la parte superior. Al centro, el jaguar, deidad de la cacería, alimento del cuerpo, y los elementos destructores de la milpa, del cultivo.

A la derecha el ojo del sol, la resurrección, la bendición de los frutos tiernos, la energía, el alimento del espíritu, el jícuri, el peyote que permite la comunicación con los dioses.

Se van destacando las oposiciones centro-periferia y arribaabajo. De esta manera, podemos definir lo encontrado hasta aquí de la siguiente manera:

Abajo centro: Los Tres Espíritus Sagrados, Tatewari, Tamatsi y Tacutsi: que son, a su vez, los Tres Grandes Antepasados (abuelos). Dios del Fuego, Dios del Pasado, (la memoria), y Diosa de la Creación de Vida (el futuro).

Centro intermedio: Tapari Tatewari: El Equilibrio de la Naturaleza. El elemento alrededor del cual gira toda la cosmogonía huichola.

Izquierda intermedia: El Equipal Sagrado volteado hacia las tinieblas, el alimento de la carne, el camino de los alacranes, la Luna, Jarianaka Metzeri, la muerte, la destrucción y la maldad.

Derecha intermedia: El Equipal Sagrado volteado hacia el Sol Naciente, hacia la luz, la resurrección, el alimento del espíritu, el camino de las mariposas, el ojo del sol; Xurawe Temai o Xarawétame, la vida, la recreación y el renacer, el Quinto Sol.

La propuesta de las Isotopías de Greimas adquiere cuerpo así, más aún en una isotopía del antagonismo:

Antagonismo Plástico: Izquierda vs. Derecha

Centro vs. Periferia

Arriba vs. Abajo 
Antagonismo Semántico: Muerte vs. Vida

Bueno vs. Malo

Pasado vs. Futuro

Construcción vs. Destrucción

La categoría abajo-arriba no puede ser totalmente determinante sin las otras dos, que son: centro-periferia e izquierdaderecha. Estas dos categorías topológicas de poco nos servirían si no se percibiera también en nuestra lectura la confrontación semántica.

El huichol debe vivir en armonía con la naturaleza que le rodea. Es responsable del equilibrio del universo, y los dioses le han encargado de ello. No puede flaquear. El conocimiento profundo de lo bueno y lo malo, del pasado y del futuro, de la vida y la muerte, de la creación y la destrucción, le permiten llegar a Wiricuta, al la cacería del jícuri, alimento del alma y contacto con los dioses.

Hemos definido los antagonismos a nivel significante. Terminemos con una propuesta de las isotopías a nivel del significado.

Hemos tratado de establecer las causas a través de las cuales la significación se establece a partir de una relación semiósica entre el plano de la expresión y el plano del contenido, en una estructura significativa (Hjemslev) que nos llevaría, a través de las isotopías del antagonismo al cuadrado semiótico, en el cual han quedado sugeridos implícitamente los términos de contrariedad y los de contradicción que encontramos en este mural, desde un acercamiento muy primario.

No podemos enfrentar esta obra del arte religioso huichol si no es desde un método de lectura en el cual la "secuencialidad" no esté determinada por una serie de tiempos continuados, como en el caso de la música o del cine. En este mural, como en todo tipo de obras similares, el tiempo narrativo está comprendido en el espacio enunciante, en el cual la co-presencia topológica y semántica marcan las posibilidades narrativas. 


\section{Bibliografia}

ÁVILA PALAFOX. R. 1989. Jornadas de Antropología. Guadalajara: Universidad Autónoma de Guadalajara.

BEASELEY, W. "The huichol indians of México." Scientific American. New York, vol.XCVIII, n.3.

BENÍTEZ, F. 1972. Los Indios de México. Tomo II. Biblioteca Era. . 1963. En la tierra mágica del Peyote. Editorial Era.

DIGGET, L. 1992. Coras y Huicholes, Vida Social y Costumbres, Centro de Estudios Mexicanos Y Centroamericanos. Instituto Nacional Indigenista.

FABILA, A. 1959. Los Huicholes de Jalisco. Instituto Nacional Indigenista.

GREIMAS, A. 1973. En torno al sentido - ensayos semióticos. Madrid: Fragua.

.; COURTÉS, J. 1979. Sémiotique. Dictionnaire raisonné de la théorie du langage. Paris: Hachette.

GRIMES, J. Y HINTON, T. 1987. "The Huichol and Cora", en The handbook of middle American Indians. Austin: University of Texas Press.

HINTON, T. 1992. Coras, Huicholes y Tepehuanes. SEP-INI.

LUMHOLTZ, K. 1997. Arte Simbólico y Decorativo de los Huicholes. Secretaría de Desarrollo Social, México.

McLEAN y ESTENÓS, R. 1982. Indios de América. México: UNAM.

MONTOYA, J. de J. 1971. Esbozo de una Axiología del Folklore. Instituto de Investigaciones Estéticas.México: UNAM.

REED B. K. 1972. Los huicholes. SEP-INI.

TALAVERA, F. 1989. La antropología y las culturas populares en el occidente de México. Guadalajara: Universidad Autónoma de Guadalajara.

SING., R. 1998. La mitología de los Huicholes. México: El Colegio de Michoacán y La Secretaría de Cultura de Jalisco. 